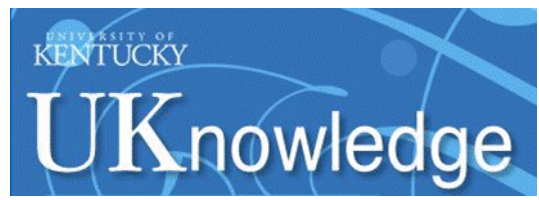

University of Kentucky

UKnowledge

\title{
A Comparative Study of Constant Power Operation Techniques for Low Inductance Machines
}

\author{
Damien Lawhorn \\ University of Kentucky, damien.lawhorn@uky.edu \\ Narges Taran \\ University of Kentucky, narges.taran@uky.edu \\ Vandana Rallabandi \\ University of Kentucky, vandana.rallabandi@uky.edu \\ Dan M. Ionel \\ University of Kentucky, dan.ionel@uky.edu
}

Follow this and additional works at: https://uknowledge.uky.edu/peik_facpub

Part of the Power and Energy Commons

Right click to open a feedback form in a new tab to let us know how this document benefits you.

\section{Repository Citation}

Lawhorn, Damien; Taran, Narges; Rallabandi, Vandana; and Ionel, Dan M., "A Comparative Study of Constant Power Operation Techniques for Low Inductance Machines" (2018). Power and Energy Institute of Kentucky Faculty Publications. 38.

https://uknowledge.uky.edu/peik_facpub/38

This Conference Proceeding is brought to you for free and open access by the Power and Energy Institute of Kentucky at UKnowledge. It has been accepted for inclusion in Power and Energy Institute of Kentucky Faculty Publications by an authorized administrator of UKnowledge. For more information, please contact UKnowledge@lsv.uky.edu. 


\title{
A Comparative Study of Constant Power Operation Techniques for Low Inductance Machines
}

\author{
Digital Object Identifier (DOI) \\ https://doi.org/10.1109/ITEC.2018.8450184
}

\section{Notes/Citation Information}

Published in 2018 IEEE Transportation Electrification Conference and Expo (ITEC).

(c) 2018 IEEE Copyright Notice. "Personal use of this material is permitted. Permission from IEEE must be obtained for all other uses, in any current or future media, including reprinting/republishing this material for advertising or promotional purposes, creating new collective works, for resale or redistribution to servers or lists, or reuse of any copyrighted component of this work in other works."

The document available for download is the authors' manuscript version that is accepted for publication. The final published version is copyrighted by IEEE and will be available as: D. Lawhorn, N. Taran, V. Rallabandi, and D. M. Ionel, "A comparative study ofconstant power operation techniques for low inductance machines," 2018 IEEE Transportation Electrification Conference and Expo (ITEC), Long Beach, CA, 2018, pp. 638-643. doi: 10.1109/ITEC.2018.8450184 


\title{
A Comparative Study of Constant Power Operation Techniques for Low Inductance Machines
}

\author{
Damien Lawhorn, Narges Taran, Vandana Rallabandi, and Dan M. Ionel, FIEEE \\ SPARK Lab, Department of Electrical and Computer Engineering \\ University of Kentucky, Lexington, KY, USA \\ damien.lawhorn@uky.edu,narges.taran@uky.edu, vandana.rallabandi@uky.edu,dan.ionel@uky.edu
}

\begin{abstract}
In traditional electric machines, it is usually possible to achieve constant power high-speed operation by employing field weakening through the injection of a negative d-axis current component. However, in machines with low armature inductance, such as high power density permanent magnet synchronous machines, and more specifically, coreless machines, which are gaining increasing attention because of their high specific torque, the extended speed range obtained using this method is very narrow. This paper summarizes the performance characteristics of existing approaches for obtaining constant power operation and proposes two new techniques, specially applicable to coreless axial flux permanent magnet machine namely, current weakening and relative winding rotation.
\end{abstract}

\section{INTRODUCTION}

Electric vehicle applications often employ permanent magnet synchronous machines (PMSM) because of their high efficiency and specific torque. These applications often require a wide constant power speed range (CPSR). In traditional PMSMs, operation in the constant power region may be achieved by the injection of a negative d-axis current, however, the range of speeds over which this is possible often tends to be small. The width of the CPSR is a strong function of the machine's d-axis inductance, and smaller values, typical of PMSMs with surface mounted permanent magnets, due to their large air-gap, often have very limited operation in this region. This issue is further exacerbated in coreless PM machines, which present a very small inductance due to the large electromagnetic airgap because of the absence of the core.

This paper discusses different methods for constant power operation of low inductance machines, and more specifically, a multi-disc coreless axial flux permanent magnet (AFPM) synchronous machine. This motor includes two stators, with coils mounted on a non-magnetic supporting structure and three permanent magnet (PM) rotors and an exploded view is seen in Fig. 1. This traction motor is proposed to be employed in the University of Kentucky (UK) solar car, which is pictured in Fig. 2a [1]. The performance comparison of different techniques for constant power operation of low inductance machines is presented. In addition, two novel methods for achieving constant power operation, particularly applicable to coreless AFPM machines, namely current weakening and relative winding rotation are proposed.

The first method involves raising the dc bus voltage of the inverter with speed, using additional power electronics stages.
The availability of wide band gap semiconductor devices with low switching loss, as well as the absence of core loss in coreless AFPM machines make such an approach feasible. The second method involves the dynamic relative rotation of the two stators in the coreless AFPM with operating speed. This reduces the flux linkage and thus, operation at very high speeds, theoretically infinite, using this technique can be achieved. Analytical equations and finite element analysis confirm the operation of this method.

\section{Problem Formulation}

The desired torque-speed characteristics in an electric vehicle application are shown in Fig. 2b. This figure shows that the torque must remain constant up to a base speed, i.e. the speed at which the machine's terminal voltage equals the maximum voltage from the inverter. Since constant power operation is desired at speeds exceeding the base value, in order to meet the dc bus voltage limitation of the inverter, the coil flux linkage must reduce with speed. The coil flux linkage is given as,

$$
\begin{gathered}
\lambda_{p m}=\frac{2}{\pi} k_{\omega 1} N_{t} k_{v g} \alpha_{i} B_{g o} \tau_{p} \ell_{F e}, \\
B_{g o}=\frac{B_{r}}{\frac{\alpha_{i}}{k_{\alpha}} \frac{\tau_{p}}{k_{b} h_{m}}+\frac{2 \mu_{m r} k_{c} k_{s o} g_{o}}{k_{h} g_{m}},}
\end{gathered}
$$

where $N_{t}$ is the number of turns per phase; $k_{v g}$, the ratio between amplitude of the fundamental wave and the average value of the air gap flux density; $\alpha_{i}$, the pole-arc/pole-pitch ratio; $B_{g o}$, the peak open-circuit air gap flux density; $\tau_{p}$, the pole pitch; $\ell_{F e}$, the back iron length; $k_{\alpha}$, the PM leakage coefficient; $k_{b}$, the number of PMs which provide polar flux; $h_{m}$, the PM height; $\mu_{m r}$, the relative permeability of the $\mathrm{PM} ; k_{c}$, Carter's coefficient; $k_{s o}$, the d-axis saturation factor at open-circuit operation; $g_{o}$, the air gap thickness; $k_{h}$, the number of times the medium length flux line passes through the PMs, and $g_{m}$, the PM thickness [2].

In the surface mounted PMSMs, the saliency ratio is unity, and the inductance may be expressed approximately as,

$$
\begin{gathered}
L_{d}=L_{q}=\frac{2 m \mu_{o}\left(k_{\omega_{1}} N_{t}\right)^{2} \tau_{p} \ell_{F e} k_{a d}}{\pi^{2} p k_{c} g_{o}}, \\
k_{a d}=\frac{k_{c} g_{o}}{k_{c} g_{o}+\frac{k_{h} g_{m}}{2 \mu_{m r}}}
\end{gathered}
$$




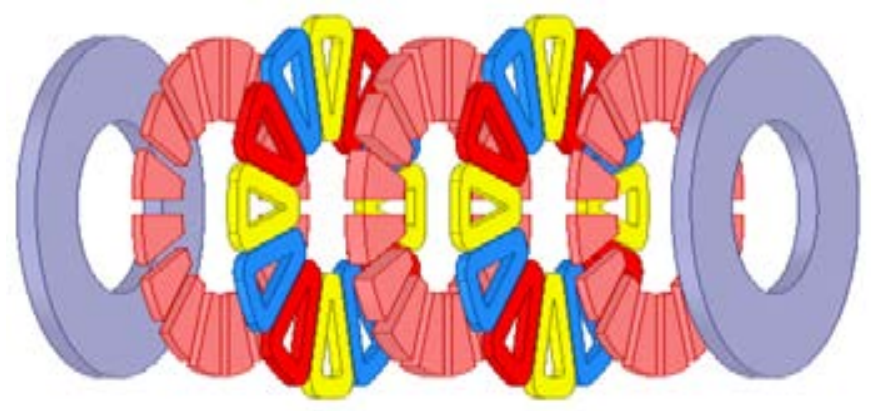

Figure 1. Exploded view of a coreless multi-disc axial flux permanent magnet machine with 2-stators and 3-rotors proposed to be used as a traction motor in the UK solar car. The stator includes coils placed in the airgap due to which the machine has a very low inductance.

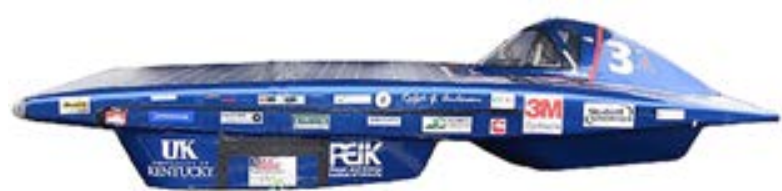

(a)

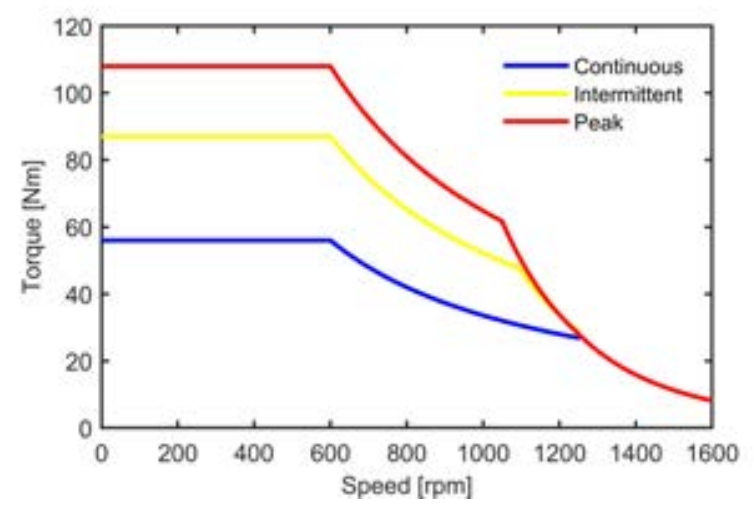

(b)

Figure 2. (a) Gato del Sol V of the University of Kentucky's Solar Car Team. (b) Desired torque-speed characteristics for the traction motor.

where $m$ is the number of phases, and $p$, the number of poles. The required terminal voltage to operate at a given angular velocity, $\omega$, is given by

$$
V=\omega \sqrt{\left(\lambda_{p m}+L_{d} I \cos \beta\right)^{2}+\left(\xi L_{d} I \sin \beta\right)^{2}},
$$

where $I$ is the motor current; $\beta$, the torque angle, and $\xi=L_{q}$ / $L_{d}$, the saliency ratio.

The electromagnetic torque produced by the machine is given by

$$
T=\frac{m}{2} p\left[\lambda_{p m} I \sin (\beta)-\frac{1}{2}(\xi-1) L_{d} I^{2} \sin (2 \beta)\right] .
$$

Since the machine is non-salient, only alignment torque is present. In a non-salient PMSM, rotor reference frame oriented control is employed to decouple the currents into direct (d) and quadrature (q) axis components. From (4), as $\xi=1$, maximum

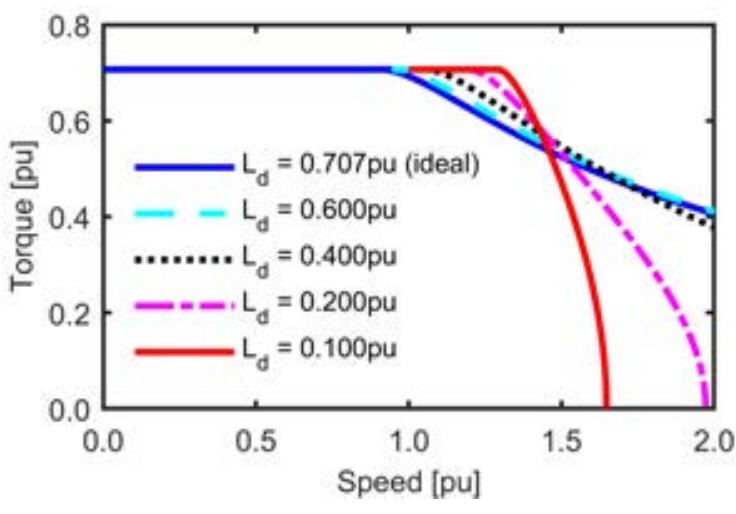

Figure 3. Torque speed characteristics of a permanent magnet synchronous machine with different values of the pu d-axis inductance. Smaller values, exhibited by the coreless AFPM machine, result in a very narrow constant power range, although a wide range is required for the application.

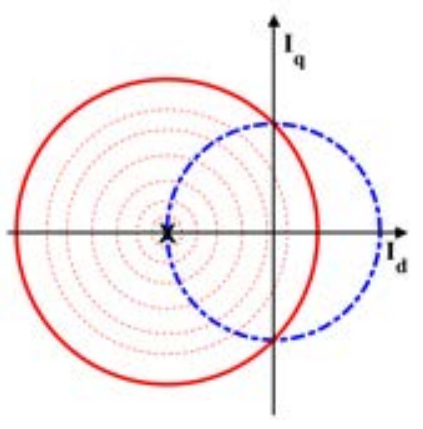

(a)

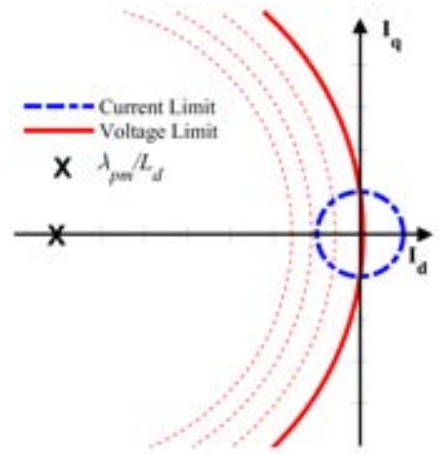

(b)
Figure 4. Motor drive operation range of two surface-PM machines, limited by voltage and current constraints. (a) A machine with a $\lambda_{p m} / L_{d}$ ratio of 1. (b) A machine with a $\lambda_{p m} / L_{d}$ ratio of 7.07. Operation is achievable in the regions encompassed by both circles. Dashed red lines indicate increasing speed.

torque per ampere is obtained when the d-axis current is driven to zero, or $\beta$ is maintained at 90 degrees. At higher speeds, a negative value of $I_{d}$ can be used to reduce the terminal voltage, otherwise directly proportional to speed, as seen in (3). The value of $I_{d}$ is increased such that the total rms phase current is constant, i.e.

$$
I_{d}^{2}+I_{q}^{2}=I_{s}^{2}
$$

where $I_{s}$ is the phase current, at $1 \mathrm{pu}$ This serves to reduce the torque, as it is directly proportional to $I_{q}$. The flux linkage reduces with increasing value of negative $I_{d}$ (i.e. $90^{\circ}<\beta<$ $180^{\circ}$ ) such that the terminal voltage is constant.

The dependence of the width of the constant power region on the value of d-axis inductance is seen in Fig. 3. Lower values of pu inductance, as typical of the coreless AFPM machine lead to a very narrow constant power region. The analytically calculated torque-speed characteristics for different values of pu $L_{d}$ are illustrated in Fig. 3. The torque-speed characteristics were calculated assuming an available terminal voltage of 1 $\mathrm{pu}$ in all machines. By setting a voltage constraint of $1 \mathrm{pu}$ 


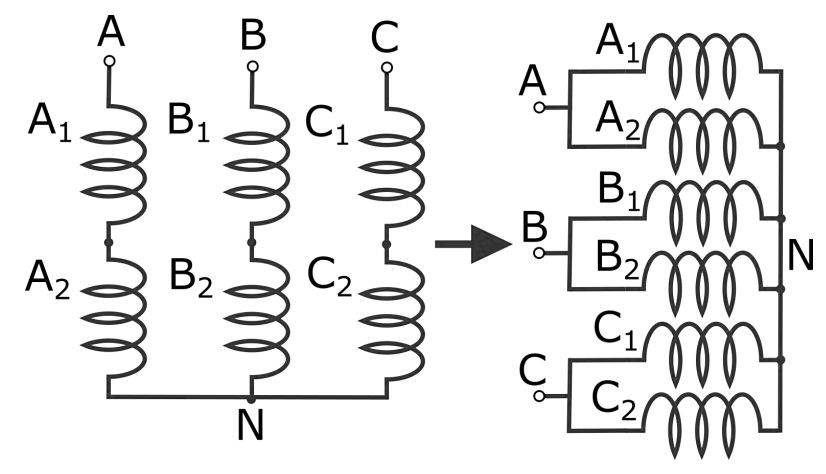

Figure 5. Schematic of winding reconfiguration. The series connection is employed at lower speeds, while at higher speeds, the coils are connected in parallel.

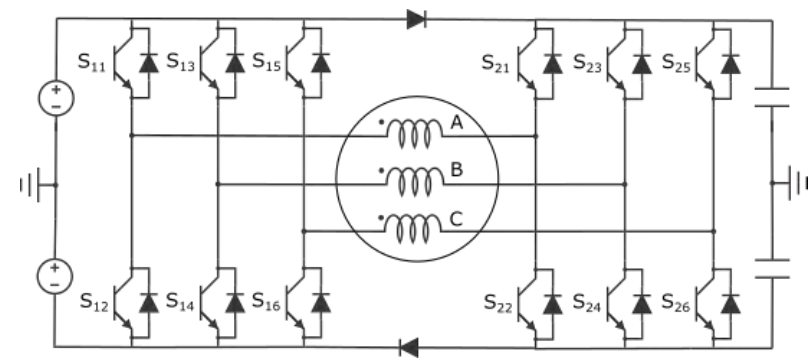

Figure 6. Schematic of a machine with open ended windings fed by two voltage source inverters.

on (5), the voltage limited capability of a machine's drive can be defined as a function of speed, inductance, flux linkage, and current. The current limitation is expressed by (7). The limitations are illustrated in Fig. 4. Operation is achievable at any point within the intersection of the voltage and current limitation circles. The radius of the voltage limitation circle is $V / \omega L_{d}$, and it is centered at $-\lambda_{p m} / L_{d}$. As the operating speed is increased, the radius reduces. The figure shows two machines, one with $L_{d}=0.707 \mathrm{pu}$, for ideal field weakening operation and the other with $L_{d}=0.1 \mathrm{pu}$, representative of a machine with ultra-low inductance, such as a coreless machine. The condition for ideal field weakening is

$$
\lambda_{p m}=L_{d} I_{s} .
$$

Since $\mathrm{V}=1 \mathrm{pu}$, and $I_{s}=1 \mathrm{pu}$, and for a surface mounted PMSM, $L_{d}=L_{q}$, the value of $\lambda_{p m}$ can be found by substituting these values in (5) to be $0.707 \mathrm{pu}$

It can be seen that for the lower inductance, the voltage limit circle has a much larger radius, and the center of the circle is shifted far from the origin due to the very small inductance. Thus, as speed is increased, the machine reaches the inoperable regions quickly and alternative methods are required to achieve operation at speeds higher than the rated speed.

\section{REviEW OF Existing Methods FOR CONSTANT POWER OPERATION}

Operation at higher speeds for machines with a small inductance may be achieved by dynamic winding re-configuration.
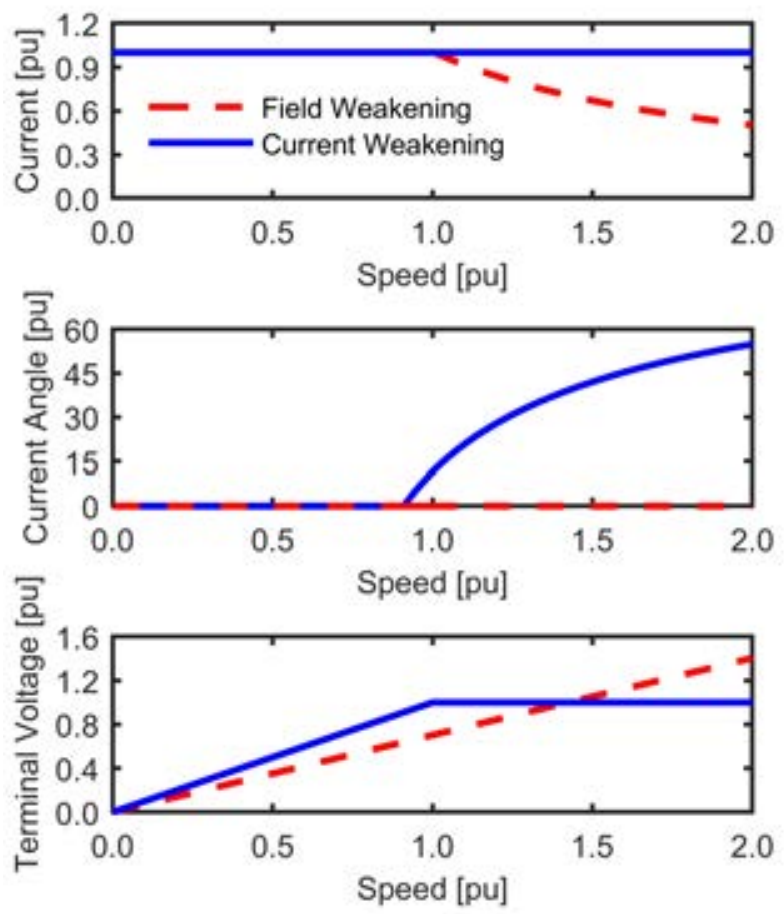

Figure 7. Current weakening technique and traditional field weakening approach in the constant power region.

For instance, in one implementation, the windings can be connected in series for operation in the constant torque region of the torque-speed characteristics, and in parallel when constant power operation is desired (Fig. 5).

This technique requires each phase winding to be divided into two sections. During the shift in configuration from series to parallel, the current and voltage per winding are maintained constant [3]. Connection of the windings in parallel leads to a reduction in the number of turns, and therefore a smaller $\lambda_{p m}$ and $L_{d}$, as indicated by equations (1) and (2), and thus, higher speed can be achieved. This method requires no daxis current to be injected, thus maximum torque per ampere (MTPA) can be maintained, as long as the maximum desired operating speed is twice the base speed. Actual implementation of this method could be achieved using back-to-back thyristors as suggested in [4].

Due to the fact that current would double when the winding configuration is switched from series to parallel, this method does add an increase in required current and therefore, voltampere rating for the inverter. However, this increase in current rating may be justified, as traction motor inverters are often over-sized in order to meet the desired acceleration at low speed.

Another method for extending the speed range involves the addition of an external inductance in series with the machine, which leads to a reduction in required terminal voltage at higher speed as seen in equation (5). This method extends 
the field weakening range of the machine. Operating speeds past the rated value can be obtained through tradition means of d-axis current injection. Since all of the current is not maintained in the q-axis in this method, MTPA is not achieved at higher speeds. The amount of external inductance added to the machine may be dynamically controlled by the required operating speed. Minimal external inductance is desired, as the reactive impedance negatively affects the power factor during operation of the machine.

In a PMSM with open ended windings, it is possible to use an additional voltage source inverter (VSI) to boost the terminal voltage to the machine. The main or primary inverter is fed from a voltage source, and the secondary inverter is housed at the output terminals of the machine and is fed by capacitors Fig. 6. In this configuration, the terminal voltage available increases by a factor of $\sqrt{3}$ [5].

Additional increase in terminal voltage can be achieved when the capacitor is charged to a greater voltage than the supply battery. In one possible implementation, equal AC voltage is applied to all the phases such that the resulting zerosequence current is used to charge the secondary inverter's feeding capacitor to a higher voltage due to the boosting effect of the winding inductances. Benefits of this method include the ability to operate at MTPA at all speeds. Unity power factor operation can be achieved by control of the secondary inverter. Additionally, the introduction of a secondary inverter adds redundancy. In the case of a primary inverter failure, the connections of this inverter can be disconnected from the battery and machine and the corresponding motor terminals may be shorted. The battery may then be connected to the DC side of the secondary inverter [6]. If the failure occurs in the secondary inverter, the same actions can be taken with the exception of exchanging the battery connection.

The main disadvantages of this method include added cost to the system through requirement of a secondary inverter, and the restriction of application to open winding machines exclusively.

\section{Electronically Controlled Current WEAKENING}

The available terminal voltage limits the maximum operating speed and therefore, increasing it would mitigate this limitation. In order to obtain constant power operation, the torque must reduce inversely with speed, which is accomplished by decreasing the q-axis component of the current as seen in Fig. 7. The phasor diagrams in Fig. 8 show how the voltage and current compare between this proposed method and the traditional field weakening approach. In the current weakening approach, the d-axis current is maintained at zero at all speeds and therefore, maximum torque per ampere is maintained. The current weakening approach may be viewed as a means of extending the constant torque region of the motor.

In a traditional field weakening approach, at high speeds, the fundamental component of the flux density in the steel is reduced such that the core losses in the machine do not become

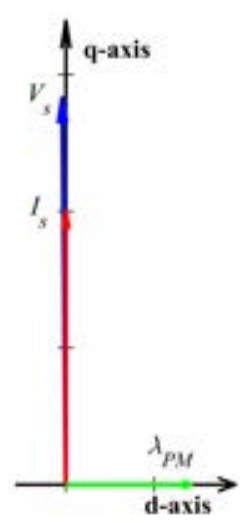

(a)

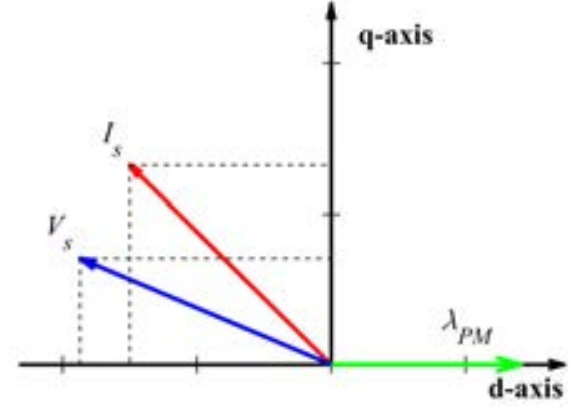

(b)
Figure 8. Phasor diagram for two generic permanent magnet machines with saliency operating at 2 pu speed and neglecting stator resistance. (a) Field weakening operation in a machine with per unit inductance of 0.707 through injection of d-axis current. (b) Current weakening operation of a machine with per unit inductance of 0.01 . In this method there is no d-axis current injection and an oversized voltage rating of the drive.

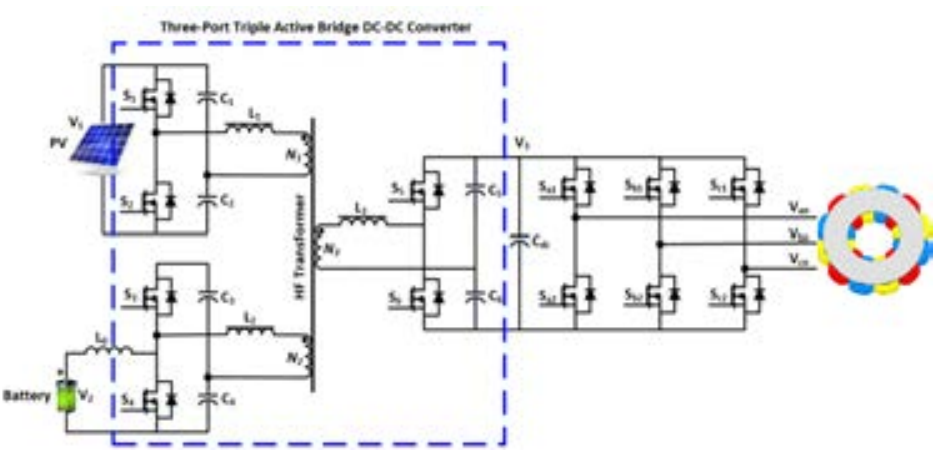

Figure 9. A three port dc-dc converter fed from solar panels and battery. A variable dc-bus voltage is provided to the inverter driving the traction motor Such a configuration can be used to implement the current weakening method.

prohibitively high. Since current weakening does not involve reduction of flux linkage and flux density, this method would lead to prohibitively high core loss in conventional machines owing to the high frequency and flux density. This can be seen in (9),

$$
P_{h y}=K_{h} f B^{1.6}, P_{e d}=K_{e} f^{2} K_{f}^{2} B^{2} .
$$

where $K_{h}$ is the hysteresis constant, $K_{e}$ is the eddy current constant, and $K_{f}$ is the form constant.

This approach becomes feasible for use in coreless machines, wherein the steel and PM losses are nearly negligible due to the large electromagnetic airgap. Although at very high operating speeds, these losses could become significant, they can be virtually eliminated by special winding techniques [7]. Thus, since most of the loss occurs in the windings, the efficiency may in fact increase with operating speed owing to reduction in $I_{q}$.

The increase in terminal voltage with operating speed can be achieved through the introduction of a either a traditional 

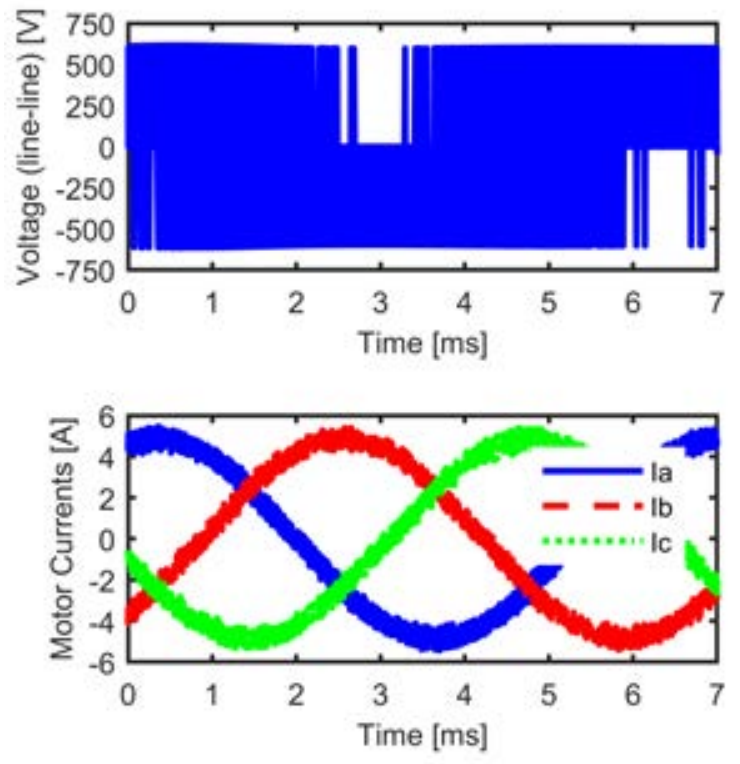

(a)
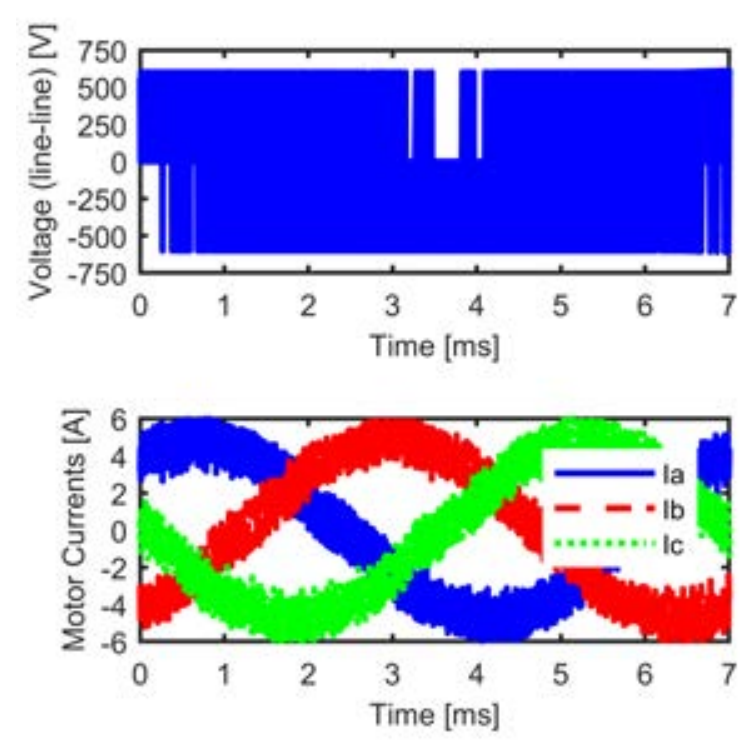

(b)

Figure 10. (a) motor phase currents and voltage of a machine with $1 \mathrm{mH}$ armature inductance, (b) motor phase currents and voltages of a machine with $0.5 \mathrm{mH}$ armature inductance.

boost stage prior to the inverter, or by the use of a multiport converter as shown in Fig. 9 [8]. Boosting the DC bus voltage requires that the inverter is rated for a higher voltage by a factor proportional to the ratio of desired speed to rated speed. Power electronics efficiency enhancements are possible if the boost stage incorporates soft switching.

The proposed technique may be suitable for use in conjunction with WBG inverters, which would be required to reduce the excessive current ripple in such low inductance machines (Fig. 10). Although the devices must be rated for the maximum dc-bus voltage, the power electronics cost may not scale in

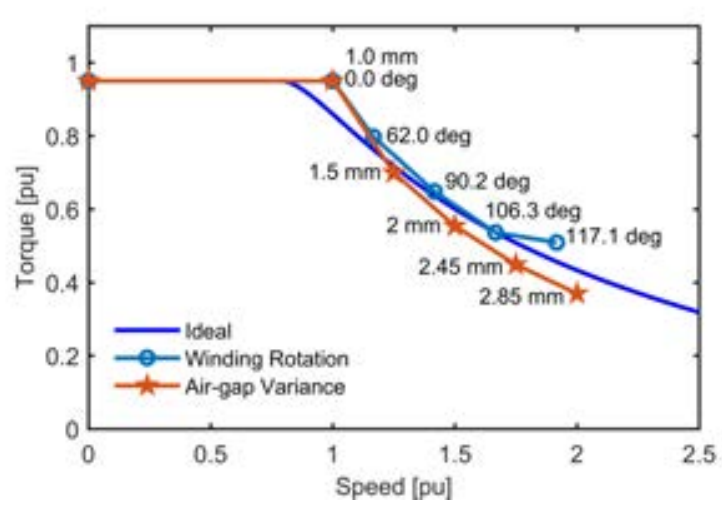

Figure 11. Torque-speed characteristics obtained using the air-gap variation and winding rotation techniques, along with the desired characteristics.

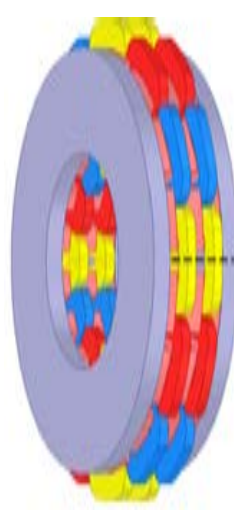

(a)

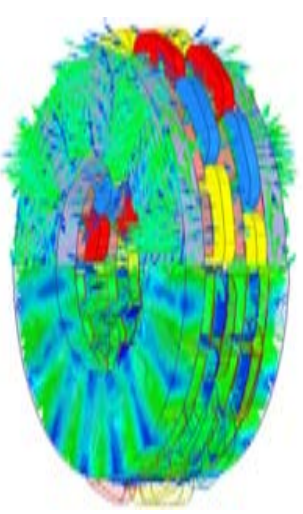

(b)

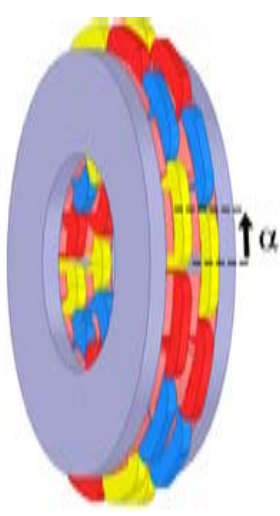

(c)
Figure 12. Constant power operation at higher speeds by relative rotation of the stators which reduces the winding factor, (a) Machine geometry without relative angular shift between the stator, (b) the 3D flux paths under these conditions, and (c) machine geometry after relative angular shift between the two stators is implemented. The shift angle, $\alpha$, can be calculated based on the desired ratio of operating speed to rated speed.

proportion with the voltage due to the smaller switching loss and heat sink requirements. The smallest rated WBG devices that meet current requirements of the motor drive which are commercially available have voltage ratings that exceed the rated voltage of the inverter present in UK's Gato del Sol by a factor of 3-4. Other benefits of this technique include the control of dc-bus voltage with load such that current ripple is always maintained within desirable limits.

\section{Mechanical Controlled Air-Gap Length And RELATIVE STATOR Rotation}

Constant power operation for axial airgap machines can also be achieved by modifying the machine mechanically as suggested in [9]. The method proposed utilizes a mechanical actuator to vary the air-gap distance dynamically. This serves to affect $\lambda_{p m}$ and $L_{d}$ as seen in equations (1) and (2).

An increase in the effective air gap, leads to a reduction in $\lambda_{p m}$, thereby permitting operation at higher speeds for a constant terrminal voltage. In [9], Heins et al. modeled the required air gap required for optimal efficiency over a given 


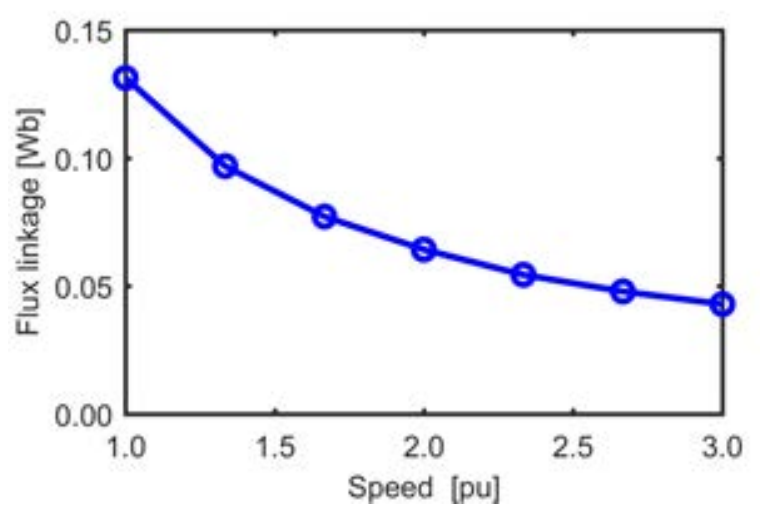

Figure 13. Flux linkage variation with shifting angle modified as a function of speed for a coreless AFPM.

torque speed characteristic curve. The results of this study have been represented in Fig. 11. This method maintains MTPA through all operating ranges as no d-axis current is required to be applied. The peak operating speed is limited by the maximum value of air-gap that maintains structural integrity of the machine.

Operation at higher speeds can also be obtained in the coreless multi-disc AFPM by dynamically rotating the two stators relative to each other with increasing speed. This reduces the coil flux linkage due to decreased winding factor. An illustration of this approach is represented in Fig. 12. The shifting angle can be chosen, depending on the desired ratio of maximum speed to base speed, and is calculated as,

$$
\begin{aligned}
k=\frac{\sin \left(\frac{m \alpha}{2}\right)}{m \sin \left(\frac{\alpha}{2}\right)} & =\frac{\sin (\alpha)}{2 \sin \left(\frac{\alpha}{2}\right)}=\cos \left(\frac{\alpha}{2}\right)=\frac{n_{r}}{n}, \\
\alpha & =2 \arccos \left(\frac{n_{r}}{n}\right),
\end{aligned}
$$

where $m$ is the number of stator discs and $\alpha$ is the shifted angle between two consecutive stator discs in electrical degrees. For this example $m=2 . n_{r}$ is the rated speed, $600 \mathrm{rpm}$, and $n$ is the operating speed.

The maximum value of $\alpha$ is 180 electrical degrees, which results in zero flux linkage, and thus it may be inferred that the maximum operating speed is limited by only the mechanical constraints. The flux linkage versus speed with shifted discs is plotted in Fig. 13. The torque speed characteristics calculated from 3D FEA for the machine in Fig. 12 at different speeds with shifted coils is shown in Fig. 11, which demonstrates the successful operation of this technique.

\section{DISCUSSION}

This paper presents a systematic review identifying the limitations of the conventional methods for low inductance machines and proposes two new methods, which are exemplified for an in-wheel solar car practical application.

The existing methods achieve a higher speed range through three fundamental modifications: increasing $L_{d}$, decreasing $\lambda_{P M}$, or increasing the available terminal voltage. By the addition of an external inductance, the field weakening range can be expanded, although at the expense of reduced power factor at the rated operating condition. Existing methods that reduce $\lambda_{P M}$ are dynamic winding reconfiguration and airgap variance, both of which achieve this through mechanical means. Finally, the existing method discussed that raises terminal voltage does so through introduction of a secondary inverter. Each of these methods have their various advantages and disadvantages.

The first proposed method, current weakening, involves raising the dc bus voltage with speed using a special power electronics arrangement. This method is particularly suitable for a coreless machine with virtually negligible core loss. Such an approach is enabled by wide band gap device technology which allows high frequency and voltage operation.

The second proposed method suggests dynamic relative rotation of stators, which reduces flux linkage, thereby allowing operation at higher speeds. Analytical equations and 3D finite element analysis confirm the operation of the machine in the constant power region by this method.

\section{ACKNOWLEDGMENT}

The authors are thankful to Greg Heins and Chris Heintz for their suggestions and technical contributions. The support of the NASA Kentucky Space Grant Consortium, University of Kentucky, the L. Stanley Pigman endowment, and ANSYS, Inc. are gratefully acknowledged.

\section{REFERENCES}

[1] N. Taran, V. Rallabandi, D. M. Ionel, and G. Heins, "A comparative study of coreless and conventional axial flux permanent magnet synchronous machines for low and high speed operation," in 2017 IEEE Energy Conversion Congress and Exposition (ECCE), Oct 2017, pp. 321-327.

[2] D. M. Ionel, J. F. Eastham, T. J. E. Miller, and E. Demeter, "Design considerations for permanent magnet synchronous motors for flux weakening applications," IEE Proceedings - Electric Power Applications, vol. 145, no. 5, pp. 435-440, Sep 1998.

[3] M. Boxriker, P. Winzer, J. Kolb, and M. Doppelbauer, "Increasing the operating range of permanent magnet synchronous motors by switching the winding configurations," in 2016 IEEE 2nd Annual Southern Power Electronics Conference (SPEC), Dec 2016, pp. 1-6.

[4] S. Hemmati and T. A. Lipo, "Field weakening of a surface mounted permanent magnet motor by winding switching," in International Symposium on Power Electronics Power Electronics, Electrical Drives, Automation and Motion, June 2012, pp. 736-740.

[5] T. Gerrits, C. G. E. Wijnands, J. J. H. Paulides, and J. L. Duarte, "Dual voltage source inverter topology extending machine operating range," in 2012 IEEE Energy Conversion Congress and Exposition (ECCE), Sept 2012, pp. 2840-2846.

[6] J. Kim, J. Jung, and K. Nam, "Dual-inverter control strategy for highspeed operation of ev induction motors," IEEE Transactions on Industrial Electronics, vol. 51, no. 2, pp. 312-320, April 2004.

[7] V. Rallabandi, N. Taran, and D. M. Ionel, "Multilayer concentrated windings for axial flux pm machines," IEEE Transactions on Magnetics, vol. 53, no. 6, pp. 1-4, June 2017.

[8] V. Rallabandi, D. Lawhorn, J. He, and D. M. Ionel, "Current weakening control of coreless afpm motor drives for solar race cars with a threeport bi-directional dc/dc converter," in 2017 IEEE 6th International Conference on Renewable Energy Research and Applications (ICRERA), Nov 2017, pp. 739-744.

[9] G. Heins, M. Thiele, D. Patterson, and N. Lambert, "Increase in operating range and efficiency for variable gap axial flux motors," in 2014 IEEE Energy Conversion Congress and Exposition (ECCE), Sept 2014, pp. 5870-5876. 